\title{
Coronavirus disease- 19 in environmental fields: a bibliometric and visualization mapping analysis
}

\author{
Shaher H. Zyoud ${ }^{1}$ (D) . Ahed H. Zyoud ${ }^{2}$
}

Received: 25 August 2020 / Accepted: 23 September 2020 / Published online: 6 October 2020 (c) Springer Nature B.V. 2020

\begin{abstract}
A coronavirus disease-19 (COVID-19) caused by a novel coronavirus has appeared in China by the end of 2019 and later recognized as a global pandemic. This pandemic has evolved as a global public health menace. It has affected every aspect of human life. In line with these concerns, governments and the scientific community react promptly to the outbreak of this pandemic. These efforts are devoted to develop vaccine and curative medicines. Further efforts are dedicated to assessing the impacts of the pandemic in relation to socioeconomic, psychological, and environmental dimensions. In this regard, it is important to follow up developments and research activities on this global issue. The present work intended to tracking the current hotspots and research trends on COVID-19 in environmental fields. Bibliometric analysis and visualization mapping were utilized with the objective of revealing and evaluating the developments in knowledge on COVID-2019 and its impacts based on a collection of environmental sources. A sum of 729 documents were collected from Scopus database limiting to environmental sources only. Of all these publications, $563(77.2 \%)$ were articles, $56(7.7 \%)$ were reviews, and $110(15.0 \%)$ were others. China has the highest share of publications $(163 ; 22.4 \%)$. It is followed by the USA $(139 ; 19.15)$, and Italy $(110 ; 15.1 \%)$. Most publications on COVID-19 were in prestigious journals. The most productive institution at global level was Chinese Academy of Sciences, China (24 documents; 3.3\%). The most prevalent topics are in relation to impacts of the pandemic on air quality, mental health, psychological, and economic aspects. The development of these topics is based on cross-sectional studies, evidence-based tools, remote sensing, satellite mapping, geographic information systems, market analysis and sampling. The progress of environmental research on COVID-19 will guide the development of global environmental strategies to control future global environmental risks.
\end{abstract}

Keywords Air quality · Content analysis · Ecosystems · Green recovery · Pandemic . Sustainability

Shaher H. Zyoud

shaher.zyoud@ptuk.edu.ps

Ahed H. Zyoud

ahedzyoud@najah.edu

1 Department of Building Engineering and Environment, Palestine Technical University (Kadoorie), Tulkarem, Palestine

2 Department of Chemistry, College of Sciences, An-Najah National University, Nablus, Palestine 


\section{Introduction}

Several cases of pneumonia of unknown causes were reported in December 2019 in Wuhan city, Hubei Province of China (Wu et al. 2020). These cases were, subsequently, linked to a newly emerged coronavirus that causes what is recognized as coronavirus disease-19 (COVID-19) (Changotra et al. 2020; Wu et al. 2020). An accelerated and vast diffusion of COVID-19 is well observed and documented across the globe. As of August 12, 2020, the World Health Organization (WHO) documented 20,162,474 confirmed cases, and 737,417 confirmed deaths in 216 countries, areas, or territories around the world (World Health Organization 2020).

The WHO declared the COVID-19 outbreak a global pandemic as the novel coronavirus continues to rapidly spread worldwide. This global pandemic has been considered as a public health emergency of global concern (Song and Karako 2020). It has affected all aspects of human life and has challenged the health care systems worldwide (Arora et al. 2020). In line with these concerns, governments and the scientific community reacted promptly to the outbreak of this pandemic. Research on COVID-19 attracted the attention of scientists and health professionals. In response to this pandemic, the developments of vaccines and curative medicines become an urgent need (Iyer et al. 2020). Epidemiology, virology, and medical sciences are, accordingly, the core themes of research that actively addressed this key issue. As well, diverse types of multidisciplinary researches on COVID19 are ongoing. That's because the risks associated with this pandemic are not just medical issues (Zhang and Shaw 2020). The COVID-2019 has multiple dimensions, and their implications are much more far reaching. It has destructive social and economic impacts. Furthermore, it imposes strong implications for psycho-social, behavioral, governance, environmental, and technological issues (Zhang and Shaw 2020).

In relation to environmental and sustainability issues, different challenges are associated with COVID-19 crisis. The understanding of the environmental conditions which favor the evolution of the pandemic, particularly when related to climate changes, variations in ecosystems, or biodiversity losses, is essential in estimating the risks. Some major concerns are found regarding medical waste management, wastewater treatment, counter impacts of air pollution, and climate changes. Otherwise, some measures (i.e., lockdown) (Rajput et al. 2020) employed to slow down and mitigate the diffusion of the pandemic have some positive impacts on the natural environment. The restrictions on transport activities, for example, contributed to significant reduction in energy consumption demanded by transportation sector (Muhammad et al. 2020). Oil demand by different industrial sectors is further declined as most industrial activities are halted worldwide (Muhammad et al. 2020). The limited social and economic activities during this pandemic resulted also in pollution reduction (Dutheil et al. 2020).

An exponential growth in publications on COVID-19 has been documented by the latest statistics (Mohadab et al. 2020). These publications provide a comprehensive overview of multidisciplinary research in relation to COVID-19 in different fields of science. The ultimate objective of this scientific enrichment in the various disciplines is to share and disseminate the findings, contributions, and advances of research related to COVID-19. This is in connection with efforts devoted to combating this pandemic and mitigating its impacts. Environmental fields of science have not been exempted from this commitment to research activities that aim to better management of the COVID-19 crisis.

Motivated by the need to explore the commitment, and achievements of environmental sciences in the battle against COVID-19 and its impacts on the environment, this study 
analyzed the status of research on COVID-19 published in a collection of environmental sources. It aims to address issues like the following: the growth trajectories and trends of environmental research during the COVID-19 pandemic outbreak, the topical foci for research regarding COVID-19 and the environment, and the research gaps in the field. Furthermore, it aims to identify the national and international contribution to this filed (i.e., the contribution of countries, institutes, authors, etc.). It will capture, analyze the current status of environmental research about COVID-2019, and develop propositions to guide future research. This will help in proposing new tracks and determine future investments in this regard.

To better approach the objectives of this study, we have taken advantage of bibliometric and new visualization techniques. Based on these techniques, different statistical and mathematical approaches to identify the main patterns, features, and structures of the underlying sciences can be utilized (Du et al. 2014). It is possible to apply such these techniques over a wide range of contexts including regions, countries, institutions, sources, different themes of research, authors, etc. (Merigó et al. 2017). The application of these techniques can be conducted at different scales ranging from micro (i.e., institution levels) to macro (i.e., global levels) (Wallin 2005). They are vastly used in different fields of science to assess frontiers of research activities qualitatively and quantitatively (Zhang et al. 2020; Zheng et al. 2017, 2018; Zyoud and Al-Jabi 2020; Zyoud and Fuchs-Hanusch 2015, 2017, 2020).

In relation to COVID-19, different bibliometric studies have been conducted at global level considering all fields of science (Kambhampati et al. 2020; Lou et al. 2020; Mao et al. 2020; Mohadab et al. 2020; Zyoud and Al-Jabi 2020). Other studies were at regional or country level (i.e., in Latin America and India) (Gallegos et al. 2020; Raju and Patil 2020), in a specific filed of science (i.e., in the field of business and management) (Verma and Gustafsson 2020), comparison between English and Chinese studies (Fan et al. 2020), or in a collection of a specific sources (i.e., nursing sources) (Oh and Kim 2020). The present study is the first of its kind that addressed COVID-19 research activities in the environmental sources. It will provide researchers with a resource that can assist in the identification of the current COVID-19 research priorities in environmental fields and other major bibliometric information.

\subsection{A brief overview of COVID-19}

The COVID-19 is caused by the Severe Acute Respiratory Syndrome coronavirus-2 (SARS-CoV-2) (Vellingiri et al. 2020; Zhai et al. 2020). The COVID-19 was named by WHO, while SARS-CoV-2 was named by the International Committee on Taxonomy of Viruses (ICTV) (Zhai et al. 2020). The SARS-CoV-2 is a member of Coronaviridae family and order Nidovirales (Harapan et al. 2020; Vellingiri et al. 2020). This family consists of two subfamilies: Coronavirinae and Torovirinae (Harapan et al. 2020). The Coronavirinae subfamily is divided into four kinds: Alphacoronavirus (i.e., human coronavirus (SARS$\mathrm{HCoV}$ ), and HCoV-NL63), Betacoronavirus (i.e., HCoV-OC43, Severe Acute Respiratory Syndrome human coronavirus (SARS-HCoV), HCoV-HKU1, and Middle East Respiratory Syndrome coronavirus (MERS-CoV)), Gammacoronavirus (i.e., viruses of birds and whales), and Deltacoronavirus (i.e., viruses isolated from birds and pigs) (Harapan et al. 2020). The SARS-CoV-2 belongs to Betacoronavirus (Vellingiri et al. 2020). It is a singlestranded enveloped RNA (+ ssRNA) virus with a size of $125 \mathrm{~nm}$ (Chen 2020). It is a zoonotic virus and can infect human and various animal species (Lu et al. 2020; Vellingiri et al. 2020). 
It is thought that intermediate hosts (mainly unidentified animals) have facilitated the transmission of SARS-CoV-2 to humans (Harapan et al. 2020), and then the human-tohuman transmission had occurred. The main mechanism of transmission of the virus may occur due to close contact with an infected person via respiratory droplets produced by cough or sneeze. Other sources of transmission could be fomites (Kampf et al. 2020). Patients infected with SARS-CoV-2 are reported to have the following symptoms: fever, cough, dyspnea, and lesion in the lungs. With the progression of the disease, pneumonia, severe pneumonia, and acute respiratory distress syndrome (ARDS) will be, respectively, the most common symptoms (Heymann and Shindo 2020; Vellingiri et al. 2020). To sustain the life of patients at this stage, there is a need for life-support interventions (i.e., using ventilators or breathing machines). The virus commonly attacks the respiratory tracts and starts the process of replication in the upper and lower respiratory tracts forming lesions (Chan et al. 2020). Furthermore, it could invade the central nervous system causing neurological diseases (Vellingiri et al. 2020). The fatality of SARS-CoV-2 is lower than that of SARS-CoV, but it is more infectious (Zhai et al. 2020). Research activities in relation to tracking, detection, and vaccine, drug, and curative medicine developments were immediately launched worldwide to combat the COVID-19 (Zhai et al. 2020). Furthermore, a variety of control measures and preventions strategies are imposed by governments in response to the perceived risks associated with this pandemic.

\section{Material and methods}

\subsection{Source database}

We utilized Scopus database to source the required information and data for this evaluation. Scopus database is considered as one of the most inclusive databases of scientific literature that includes different types of publications in addition to sufficient relevant information (Romero and Portillo-Salido 2019). It is one of four most renowned databases commonly utilized to conducting different bibliometric analyses. This collection of renowned databases comprises PubMed, Scopus, Web of Science, and Google Scholar (Falagas et al. 2008). Scopus and Web of Science mainly adopt specific measures and standards in the inclusion of selected sources (Martín-Martín et al. 2018). The major features that distinguish Scopus database from other databases involve: it has higher flexibility in relation to awarding an inclusive overview on various scientific research fields (Yataganbaba and Kurtbaş 2016), and it has robust instruments of search and analysis that help in performing advanced evaluations on the collected data (Zyoud and Fuchs-Hanusch 2020).

\subsection{Search design strategy}

To compiling the required information and data for the present assessment, all subjects' fields in Scopus database (i.e., physical, health, life, and social sciences) are considered. We benefited from a recent bibliometric work on COVID-19 to consider the required terms and keywords in relation to COVID-19 (Zyoud and Al-Jabi 2020). The keywords and terms that have been included in the search query in titles and abstracts include: COVID 19; 2019 novel coronavirus; coronavirus 2019; coronavirus disease 2019; 2019-novel CoV; 2019 ncov; COVID 2019; COVID19; corona virus 2019; "nCoV-2019; nCoV2019; nCoV 2019; 2019-ncov; COVID-19"; Severe acute respiratory syndrome coronavirus 2; 
and SARS-CoV-2. It is followed by limiting the search in just the environmental sources. The search and collection of the required data were performed all within 1 day, August 8, 2020. This aimed to avoid any bias that could result from continuous updating of Scopus database.

The final query string in the advanced search was as follows: TITLE-ABS ("COVID 19" OR "2019 novel coronavirus" OR "coronavirus 2019" OR "coronavirus disease 2019" OR “2019-novel CoV” OR "2019 ncov" OR "COVID 2019” OR “COVID19” OR “corona virus 2019” OR “nCoV-2019” OR “nCoV2019” OR “nCoV 2019” OR “2019-ncov” OR "COVID-19” OR "Severe acute respiratory syndrome coronavirus 2" OR "SARS-CoV-2") AND SRCTITLE ("environ*”).

In Scopus database, phrases bounded by double quotes are deemed as a whole (one unit). These terms will be seen together in the exact order as in the searched form. The wildcard (*) is commonly utilized to capturing all likely occurrences of considered terms (i.e., environ* could be environment or environmental). The Boolean operators OR and AND are utilized to merging the various components of the search query.

\subsection{Data analysis}

The collected data were exported to Microsoft Excel for further analysis and assessment. The main information comprises countries of origin, sources, titles, authors, year of publication, affiliations, type of document, fields of interest, funding sources, keywords, languages, citations frequency, etc. We have considered the number of published documents as a quantitative indicator that indicates the research productivity of an author, country, institution, source, etc. The impact of published works was assessed using various qualitative indicators (i.e., frequency of citations, average of citations, their median, and interquartile ranges). Descriptive statistics in this regard were performed using SPSS program.

Hirsch index ( $h$-index) was used to assess the quality of research. (Hirsch 2005). This index merged quantitative measures (i.e., productivity) and qualitative measures (i.e., frequency of citations). It can be interpreted as the number of published works by either country, source, institution, or author that are possessing citations rates equal to or greater than $h$ (Hirsch 2005). This index has high potential in identifying the influence and value of the accumulated scientific research contributions (Meho and Rogers 2008). To demonstrating its notion while applied to assess the influence of a specific source, it is right to say that a source with an $h$-index of 20, for example, is having 20 documents and each document has attracted at least 20 citations at the time of the assessment. The Standard Competition Ranking (SCR) formula was utilized to sort sources, authors, countries, institutions, etc., with prominence achievements in descending order.

\subsection{Visualization mapping, clustering techniques, and content analysis}

Visualization techniques help in generating maps of knowledge, assessing the progress and frontiers of research, and identifying the hotspots and trends of research (Chen 2004). In this regard, co-authorship, co-citation, and co-occurrence analyses are among the most commonly used approaches. To assess co-authorships' links between authors or countries, co-authorship analysis, for example, can be employed. It can shed light on links of collaboration between authors from different regions across the globe. This can be employed constructively to boost research collaborations among authors. In revealing the relationships of collaborations among authors, authors who are appearing frequently having closer research 
links compared to others. This assists in identifying potential research collaborators in a particular theme of research. In the case of co-citation analysis, it aims to assess the links of co-citation between two works, for example, that are cited together by a third research piece. This assists researchers in recognizing the intellectual bases of a certain discipline relied on the strengths of links between different research works. Moreover, it helps in recognizing research trends and frontiers, scholars with much value, and other relevant bibliometric information (Chen 2004).

Visualization maps were generated in the present analysis using VOSviewer software (van Eck and Waltman 2010). VOSviewer uses clustering methods and similarity mapping to establish bibliometric maps of sources, authors, etc. Keywords maps (i.e., author keywords, index keywords, or author and index keywords at a once time) can be also produced relied on co-occurrence analysis (van Eck and Waltman 2010). In terms of countries' research collaboration, VOSviewer can create two dimensions' distance-based maps. The distance between two countries on the map, for example, is an indicator of the strength of research collaboration between them (van Eck and Waltman 2010). The more joint research works between two countries, the closer the distance between the two countries on the map (Bornmann 2016).

The word frequency and co-occurrence keyword analysis was conducted to assess the contents of published research works. Such this analysis is fundamental as core keywords demonstrate the core and hub of literature and ongoing research activities in a certain field of research (Wang et al. 2017). Furthermore, it helps in recognizing the associations and relationships between the ideas and concepts of various research works, and the hot themes that will keep active. A threshold in relation to a minimum number of documents, citations, and occurrences was applied to right visualizing the networks (Aleixandre-Benavent et al. 2017).

The most prevalent topics in the most prolific sources were identified using content analysis of abstracts. It is important to recognize the current and emerging subjects and other topics that no longer of significant concern. The abstracts on COVID-19 published in the top sources have been exported to NVivo 12, Qualitative Data Analysis Software (QSR International) (NVIVO 2020). It is followed by performing distribution analysis of words frequencies. The grouping of words relied on terms and their stemmed words. This tactic has more flexibility than the one using exact matches. Tag clouds were used to demonstrate the outcomes in visual illustration. The size of each word ("tag") is in ratio with its frequency of occurrence in the source.

\section{Results and discussion}

At time of data collection, publications on COVID-19 in all fields of science were 37,201 documents. These documents are distributed as follows: article $(18,815 ; 50.8 \%)$, letter $(7676 ; 20.6 \%)$, review $(3935 ; 10.6 \%)$, note $(3080 ; 8.3 \%)$, editorial $(2863 ; 7.7 \%)$, short survey $(363 ; 1.0 \%)$, erratum $(245 ; 0.7 \%)$, conference paper $(174 ; 0.5 \%)$, data paper $(38 ; 0.1 \%)$, book chapter $(8 ; 0.02 \%)$, conference review $(2 ; 0.01 \%)$, and retracted $(2 ; 0.01 \%)$. By looking at bibliometric studies conducted earlier on COVID-19, statistics indicate that there has been an exponential increase in the number of publications since the discovery of COVID19 pandemic. For instance, the bibliometric work of Mohadab et al. (2020) conducted on COVID-2019 on May 2020 is based on 10,228 documents extracted from Scopus database, while the work of Zyoud and Al-Jabi (2020) on June 2020 is based on 19,044 documents 
collected from the same database. This exponential increase is attributed to fostering of research and developments on COVID-19 which became a priority at the agenda of policy makers and scientists in different fields of science. Moreover, other factors contributed to this rapid increase in publications during this short period include: as a global pandemic, COVID-19 has impacted the global health, scientists have much time to report and disseminate their works due to lockdown in most countries, and the positive response of journals in terms of considering works on COVID-19 as a top priority (Kambhampati et al. 2020).

By limiting the search to environmental sources, the figure turned into 729 documents distributed as follows: article (563; 77.2\%), review (56; 7.7\%), letter $(36 ; 4.9 \%)$, editorial $(31 ; 4.3 \%)$, note $(30 ; 4.1 \%)$, short survey $(5 ; 0.7 \%)$, conference paper $(4 ; 0.5 \%)$, and erratum $(4 ; 0.5 \%)$. The contribution of environmental sources to COVID-19 literature is around 2.0\%. As COVID-2019 has attacked the core of human existence, the responses to the pandemic outbreak were devoted, primarily, to save lives. Therefore, much ongoing efforts have been intensively assigned to develop curative medicines and vaccines. The active sectors in this regard were medicine and biology. The measures taken to limit the spread and impact of COVID-19, mainly lockdown and restrictions on mobility, had adverse impacts on economy, businesses, environment, and society. All this entailed the need to extend COVID-19 pandemic-related research to the fields of business, socioeconomics, environment, etc. Concerning the environmental field and despite its modest contribution to COVID-19 at its early stages, the impact of COVID-19 will continue to attract researchers in environmental fields to foster research activities on this issue and bringing new perspectives in this regard.

The worldwide view of the research output of countries across the globe is displayed in Fig. 1. Eighty-four countries had dissimilar contributions ranging from 163 documents $(22.0 \%)$ as the case of China, which is in the forefront, to just 1 document/country as the case of a group of 23 countries across the globe. The dissimilar performance among countries can be attributed to the following factors: wealth of the country, population size, development level, scientific capabilities, and national scientific infrastructure. Another major factor is in relation to the prevalence rate of COVID-19 in different countries. The top productive countries are displayed in Table 1 which demonstrates the

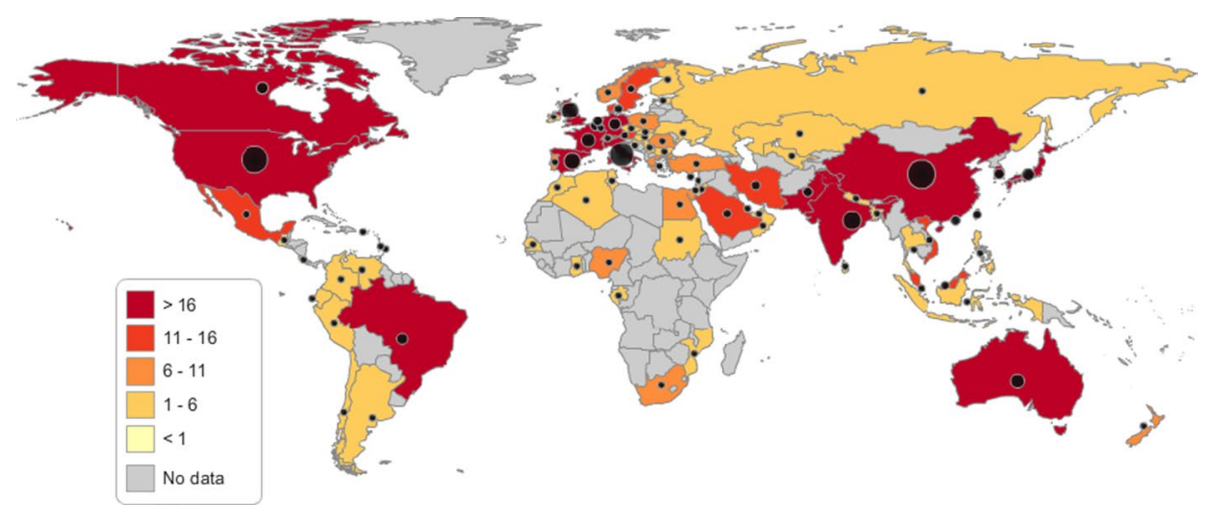

Fig. 1 Nation-level production on COVID-19 linked to environmental fields; worldwide view of the research output of countries. The color intensity represents the number of publications. The volume of black circles indicates the productivity of each country (i.e., the larger circle, the higher contribution of country in terms of number of published documents). Global map was generated by Statplanet Interactive Mapping and Visualization Software, www.statsilk.com, free license 


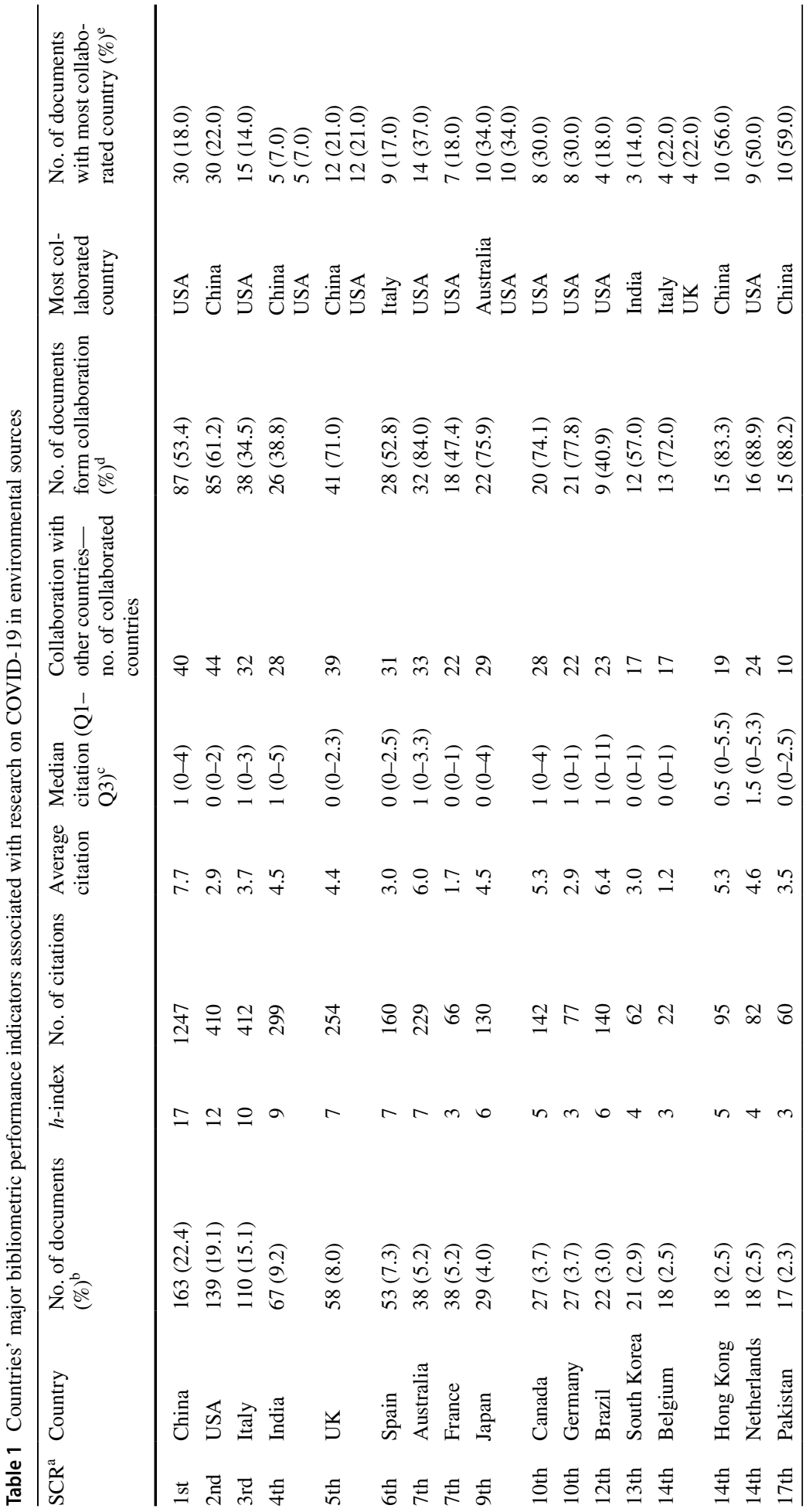




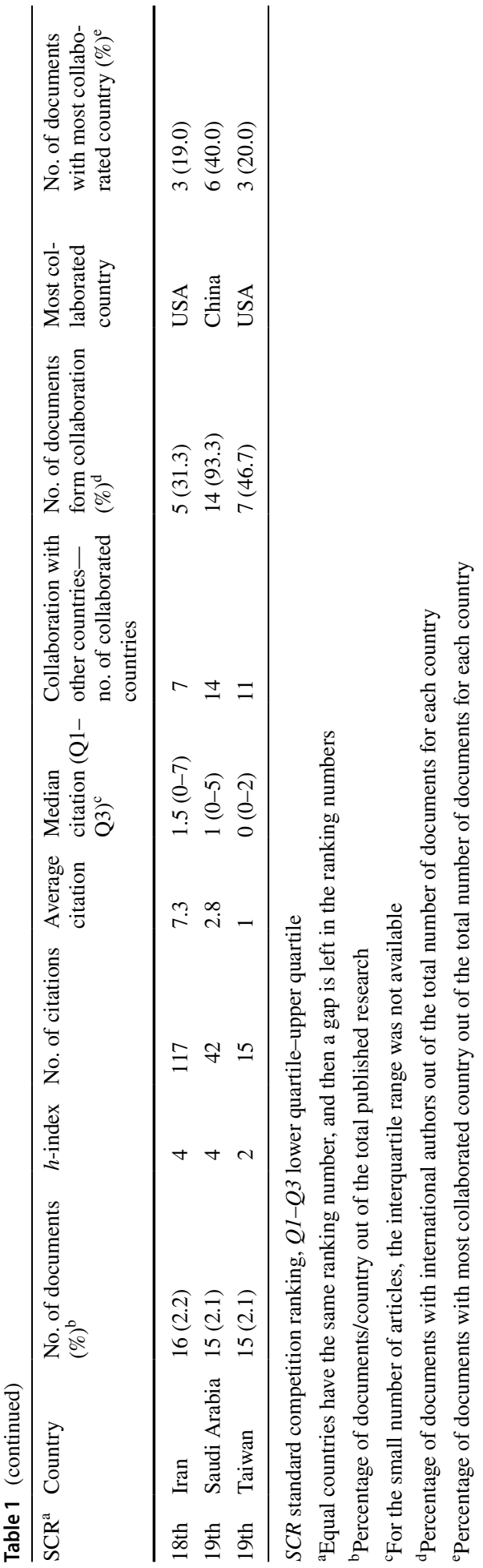


major bibliometric performance indicators. China (163 documents; 22.4\%), USA (139 documents; 19.1\%), and Italy (110 documents; 15.1\%) showed remarkable achievements in terms of productivity, h-index, and collected citations with a clear superiority of China. The global overview of COVID-19-related research activities shows distinctive performance of developed countries in addition to China, India, and Brazil. This is due to the fact that principles and concepts of the environmental measures are well affirmed and grounded in science and research in the developed world earlier compared to other regions. Moreover, the environmental and economic performances are associated with each other. When a country has the ability to ensure good living conditions to its people with regard to social, environmental, and economic aspects, this will lead to a positive impact on the environmental performance. The high growth rates in a region offer flexible capacities to tackle and resolve different environmental issues as the necessary financial resources to save the environment are available. Generally speaking, the developed countries invest significant resources (i.e., money, manpower, and materials) in environmental scientific research. Not surprisingly, these countries have emerged as worldwide leaders in environmental research related to COVID-19. Meanwhile, some developing countries like China, India, and Brazil experience remarkable shifts in policies toward reinforcing environmental measures and research, suggesting that these countries have become more significant players in environmental research. All these factors are in association with a major factor that must be not overlooked which is concerned with the prevalence rates of the pandemic. This enforces countries with high prevalence rates to struggle hard at all levels to combat the impacts associated with the spread diffusion of COVID-19. The leading role played by China, USA, and Italy that is revealed by this analysis on COVID-19 is attributed to the high prevalence rates of COVID-19 in those countries witnessing the first outbreak (Zyoud and AlJabi 2020).

The research collaboration among countries on COVID-19 in environmental sources is displayed in Fig. 2. It is demonstrated by the aid of a space of two dimensions based on co-authorship links between countries. Such this collaboration is of advantage in producing high impact scientific research based on complementary practices, skills, and experiences (Havemann et al. 2006). During this crisis, the teaming up of countries and research centers across the globe is of high advantage in reaching efficient solutions to combat the pandemic. In the visualization map, as shown in Fig. 2, countries with highest links of coauthorship are appeared close to each other. Assigning countries with frequent collaborators to clusters can be recognized based on a specific color/cluster. The size of the node indicates the performance of each country regarding co-authorship and collaboration. The minimum number of documents of a country was defined as 10 documents. Of 99 countries, there were 27 countries that met this specified threshold. There were 209 links of collaboration with a total strength of 658. The USA had the highest number of links and the highest link strength; 26 links with a total strength of 172. It is followed by China that had 25 links with a total strength of 140, Australia had 23 links with a total strength of 95, UK had 22 links with a total strength of 95, and Italy that had 20 links with a total strength of 90. The strongest link (total link strength: 30) was between USA and China. The two countries have had the highest rate of collaboration at the global level. The second strongest link (total link strength: 15) was between USA and Italy. The three countries, USA, China, and Italy, were the most affected regions at the early outbreak of the pandemic. The frequently collaborated countries were categorized into 4 clusters. Cluster 1 , red color, includes 9 countries with UK in the core. Cluster 2, green color, includes 8 countries with USA in the core. Cluster 3, blue color, includes 8 countries with China in the core. The last cluster, cluster 4, of yellow color includes 2 countries and Hong Kong was in the core. 


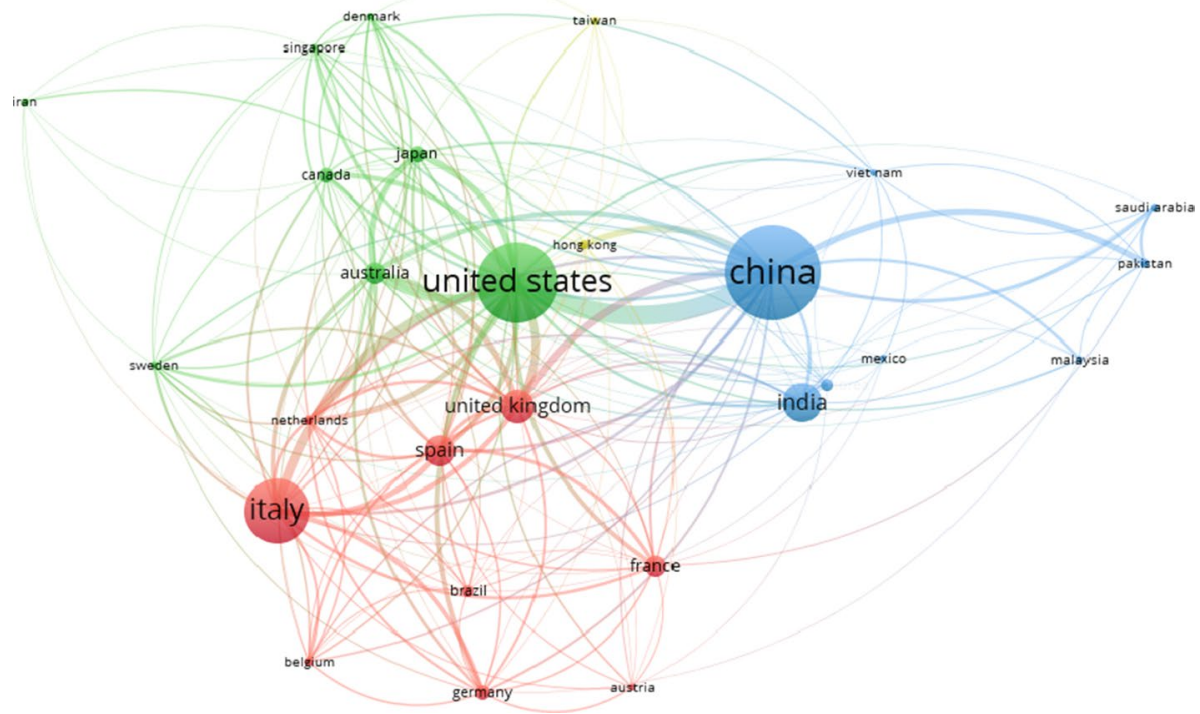

Fig. 2 Network visualization map of country collaboration. A minimum of 10 documents per the country was set as a threshold, and 27 countries meet the threshold. The thickness of the link between any two countries is an indicator of the strength of collaboration between the two countries. The volume of the circle around the item is an indicator of the contribution of the item (i.e., the larger the circle, the higher the contribution of country in terms of co-authorship). The items with same color indicate that these items are related to each other (i.e., within the same cluster)

Researchers across the globe have published their works on COVID-19 in 80 environmental journals. Of these, 36 have published only 1 document/journal, 15 journals have published 2 documents/journal, and 5 journals have published 3 documents/journal. The other journals with productivity more than 4 documents/journal are displayed in Table 2. Amongst the top 20 journals shown in Table 2 International Journal of Environmental Research and Public Health with IF, 2019=2.849, published the largest number of documents in COVID-19 $(n=264 ; 36.2 \%)$, followed by Science of the Total Environment $(n=188 ; 25.8 \%, \mathrm{IF}=6.551)$, and Environmental Research $(n=30 ; 4.1 \%, \mathrm{IF}=5.715)$. The current analysis showed that most of publications on COVID-19 have been published in prestigious journals with impact factors. Many journals, including leading environmental journals with high impact factors, assigned special issues on COVID-19. Works on COVID-19 have been considered as a priority and published in an open access model (Kambhampati et al. 2020). Science of the Total Environment journal collected the highest number of citations at the time of data collection (1437), followed by International Journal of Environmental Research and Public Health (878) and Environmental Pollution (147).

The visualization maps of most prolific journals based on co-citation analysis are displayed in Fig. 3a: Network visualization map, and Fig. 3b: Density visualization map. The minimum number of citations of a source was fixed as 100. Out of 9306 sources, 15 met the specified threshold. The total links were 103 with a total strength of 18,214. Science of the Total Environment journal had the strongest link strength (7608), followed by Lancet (4616), and New England Journal of Medicine (2826). The strongest link (1097) was between Science of the Total Environment journal and Atmospheric Environment journal 


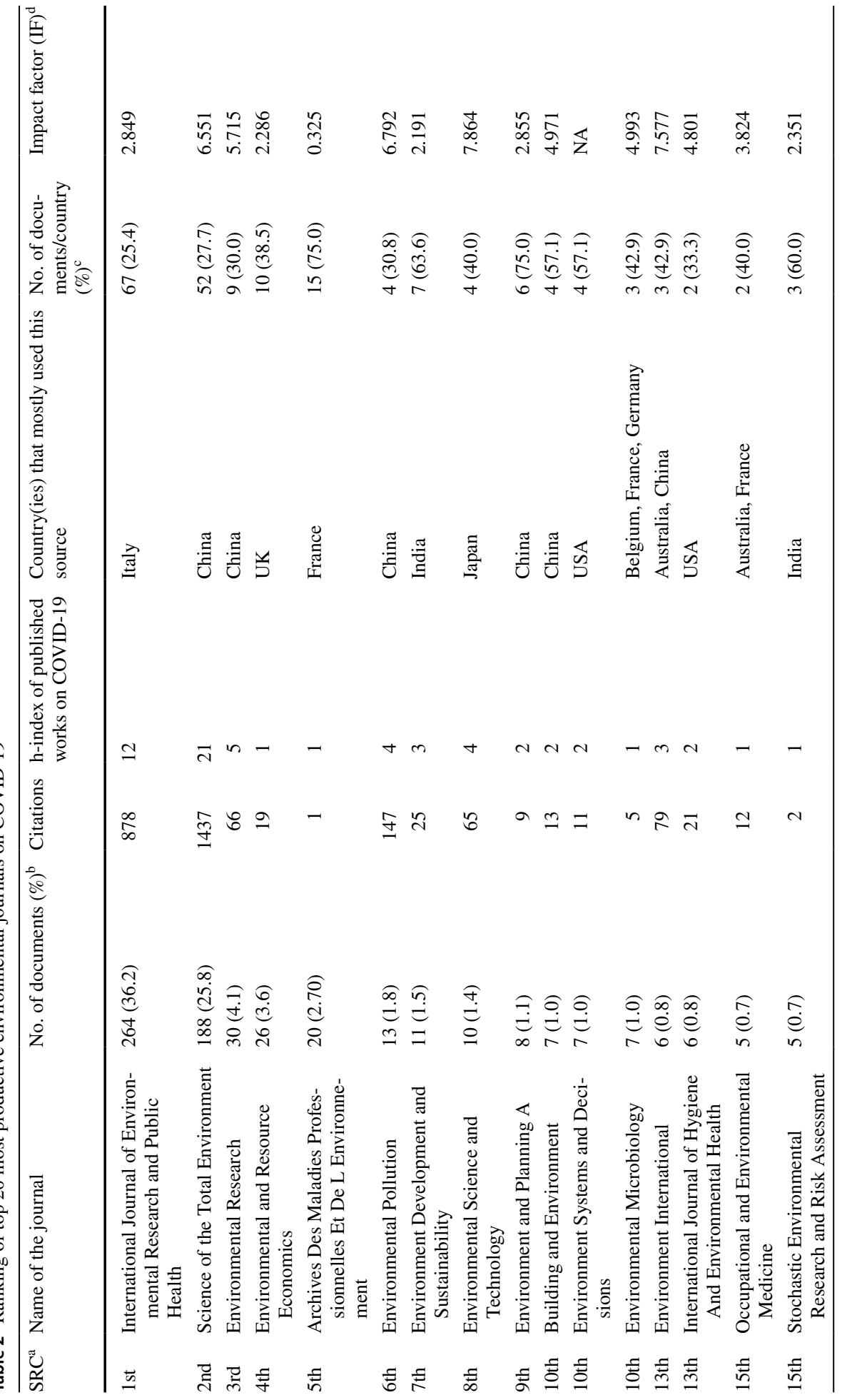




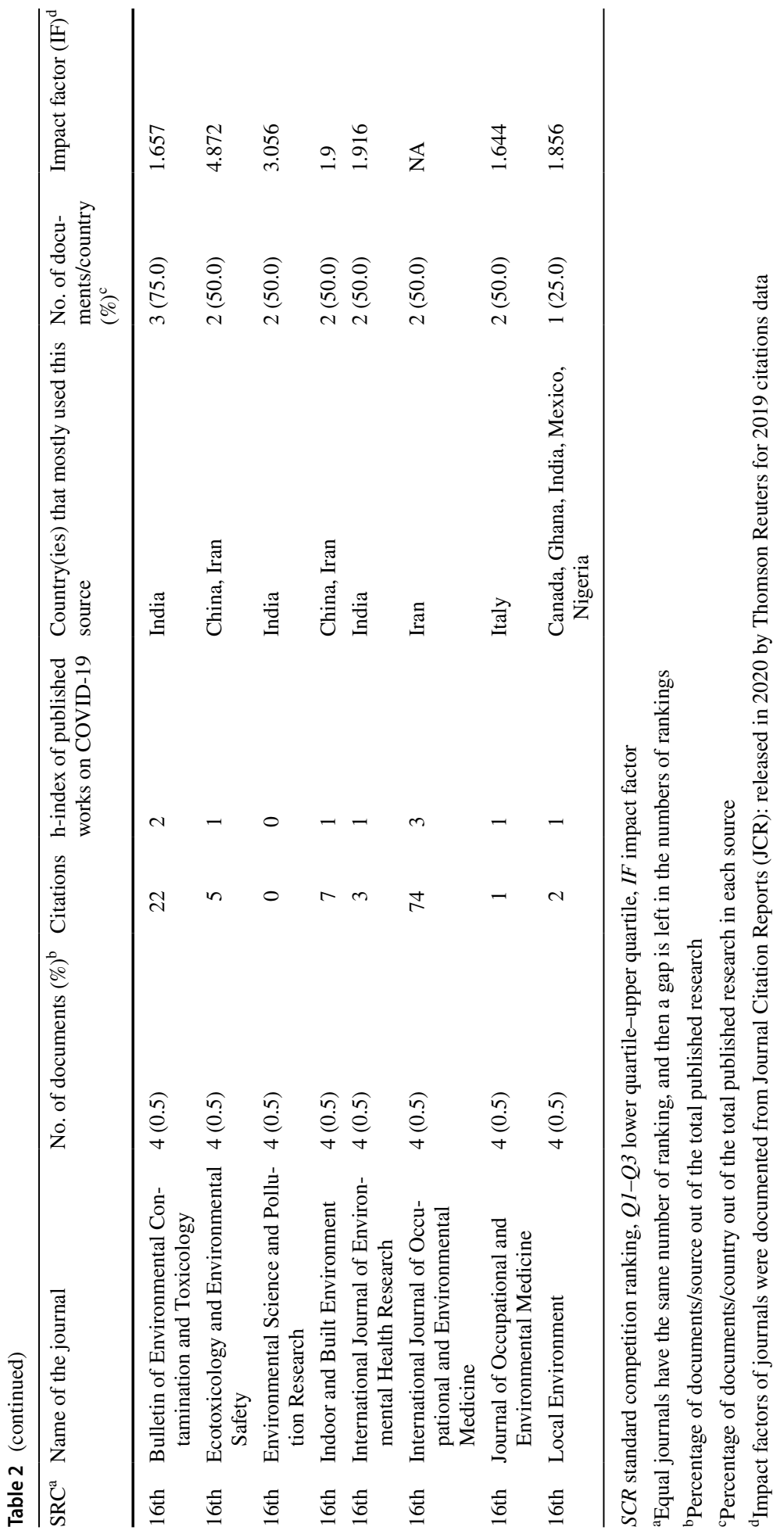


A

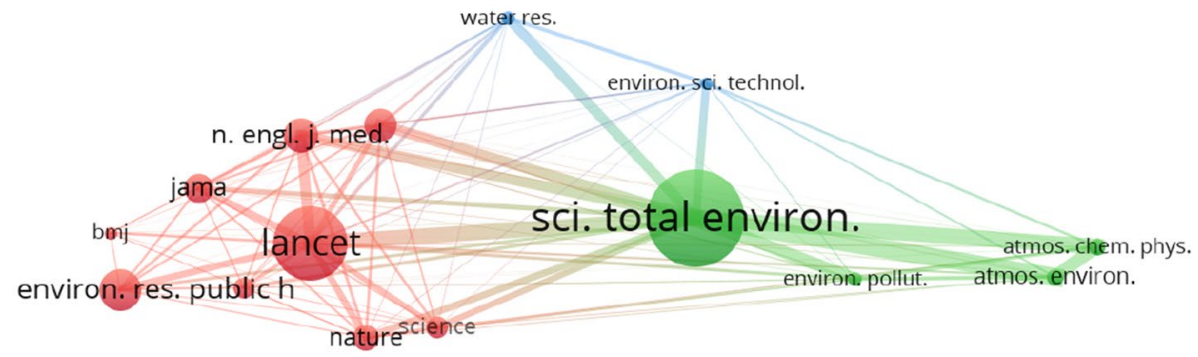

B

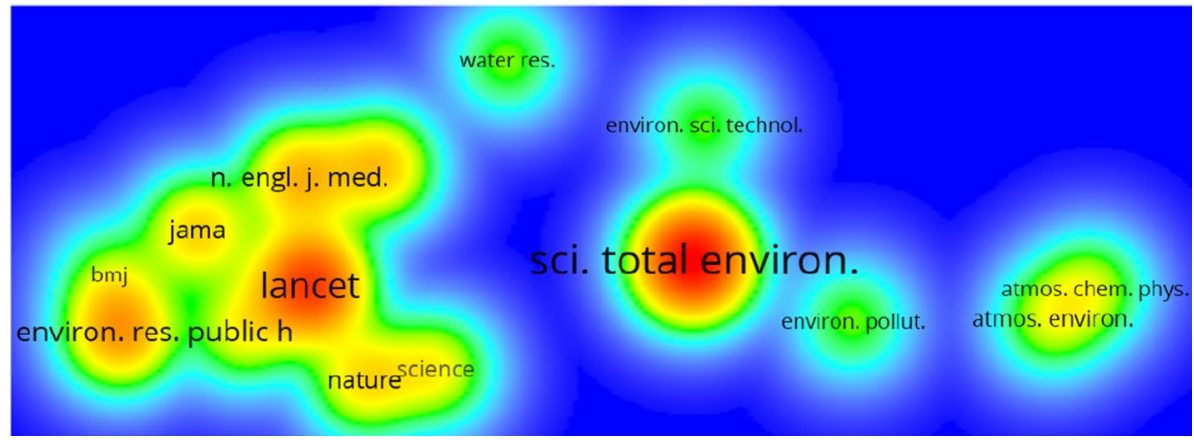

Fig. 3 Visualization maps of top journals based on co-citation analysis; a network visualization map; b density visualization map. A minimum number of citations of a source: 100 . Of the 9306 sources, 15 met the threshold. For each of the 15 sources, the total strength of co-citation links with other sources was calculated. The sources with the greatest total link strength are selected

(Fig. 3a). This analysis shows the importance of topics addressed on COVID-19 in environmental sources as they are cited together with works on COVID-19 that have been addressed by well-reputable journals in fields of medicine, public health, science, technology, and natural sciences. This includes New England Journal of Medicine, Science, Nature, The British Medical Journal and Lancet journals. Three clusters of sources have been identified by this analysis. Cluster 1 , red color, includes 9 journals closely in terms of scope. The Lancet journal is in the core of this cluster. Cluster 2, green color, includes 4 sources and Science of the Total Environment journal is in the core. The last cluster, cluster 3 , of blue color includes 2 sources and Water Research journal is in the core. The zones of the red color in Fig. $3 \mathrm{~b}$ indicate active sources that are having the highest rate of co-citation (i.e., Science of the Total Environment and Lancet).

The published works on COVID-19 attracted 3007 citations with an average of 4.1, median (interquartile range): $0(0-2)$. The h-index is 27 that means 27 documents had attracted at least 27 citations/document at the time of data collection. The top 20 most cited publications are displayed in Table 3 (Ahmed et al. 2020; Conticini et al. 2020; Dutheil et al. 2020; Habibzadeh and Stoneman 2020; Li et al. 2020; Liu et al. 2020; Ma et al. 2020; Morawska and Cao 2020; Muhammad et al. 2020; Ogen 2020; Setti et al. 2020; Sharma et al. 2020; Tobías et al. 2020; Tosepu et al. 2020; Vellingiri et al. 2020; Wang et al. 2020; Xie and Zhu 2020; Zambrano-Monserrate et al. 2020; Zhang and Ma 2020; Zhu et al. 2020). Twelve documents out of 20 documents in the list of most cited articles 


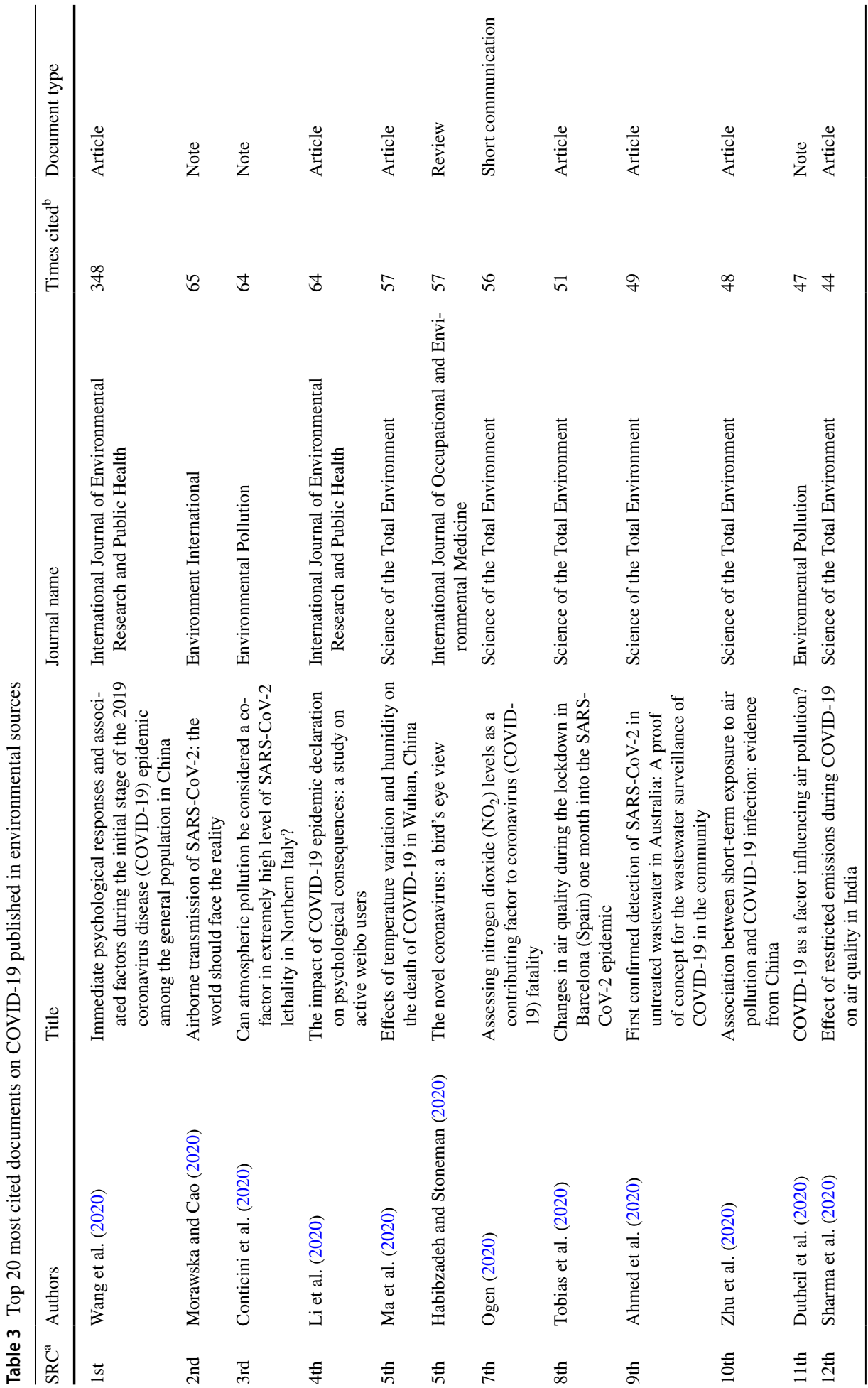




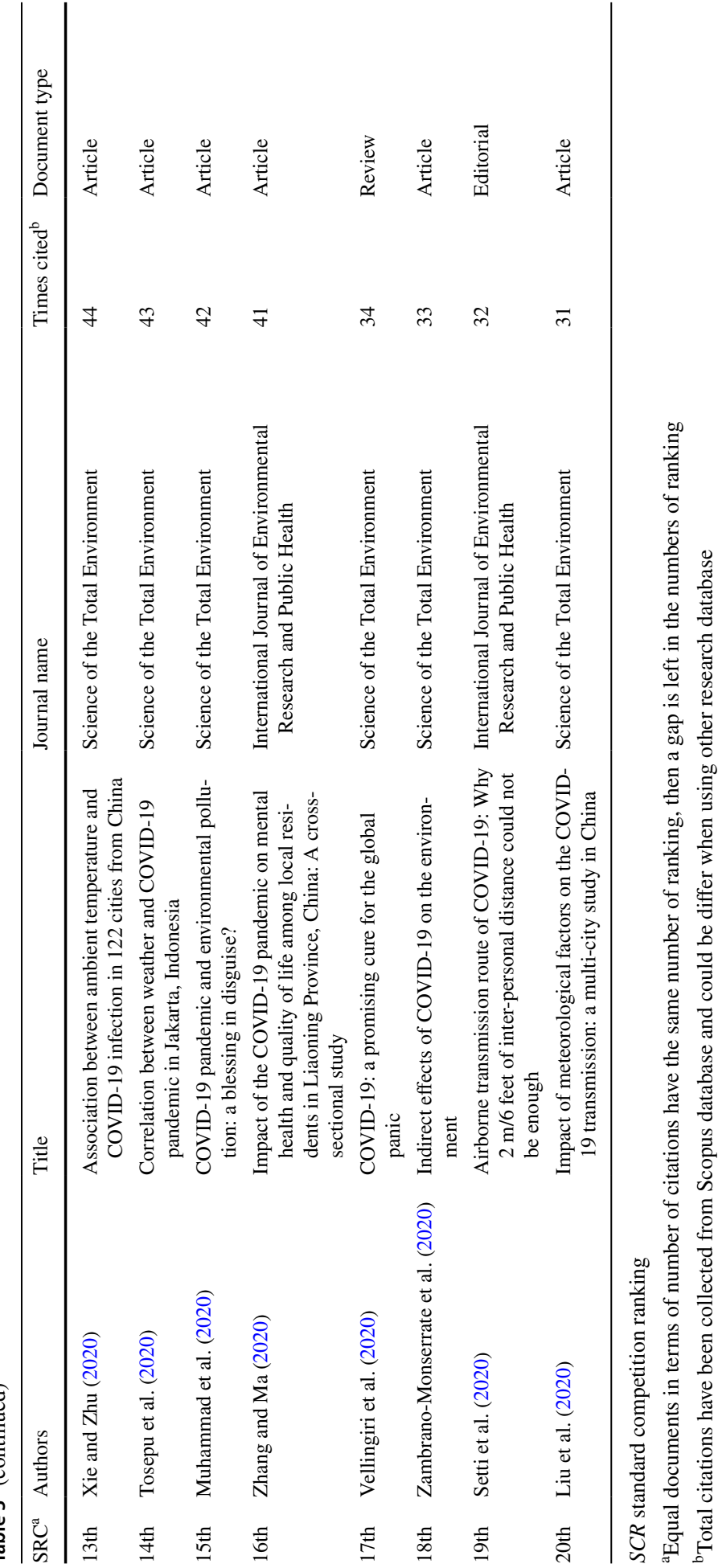


Table 4 Top 20 most productive institutions on COVID-19

\begin{tabular}{|c|c|c|}
\hline $\mathrm{SRC}^{\mathrm{a}}$ & Name of the institution & $\begin{array}{l}\text { No. of } \\
\text { documents } \\
(\%)\end{array}$ \\
\hline $1 \mathrm{st}$ & Chinese Academy of Sciences, China & $24(3.3)$ \\
\hline 2nd & University of Chinese Academy of Sciences, China & $15(2.1)$ \\
\hline $3 \mathrm{rd}$ & Università degli Studi di Napoli Federico II, Italy & $14(1.9)$ \\
\hline 4th & Peking University, China & $13(1.8)$ \\
\hline 4 th & Università degli Studi di Milano, Italy & $13(1.8)$ \\
\hline 6 th & Zhejiang University, China & $11(1.5)$ \\
\hline 6 th & CNRS Centre National de la Recherche Scientifique, France & $11(1.5)$ \\
\hline 8 th & Università degli Studi di Bari, Italy & $9(1.2)$ \\
\hline 9 th & Inserm, France & $8(1.1)$ \\
\hline 9 th & Consiglio Nazionale delle Ricerche, Italy & $8(1.1)$ \\
\hline 9 th & KU Leuven, Belgium & $8(1.1)$ \\
\hline 9 th & Tsinghua University, China & $8(1.1)$ \\
\hline 9 th & $\begin{array}{l}\text { CSIC_-Instituto de Diagnostico Ambiental y Estudios del Agua IDAEA, } \\
\text { Spain }\end{array}$ & $8(1.1)$ \\
\hline 14 th & $\begin{array}{l}\text { Research Center for Eco-Environmental Sciences Chinese Academy of } \\
\text { Sciences, China }\end{array}$ & $7(1.0)$ \\
\hline 14 th & Università degli Studi di Roma La Sapienza, Italy & $7(1.0)$ \\
\hline 16th & Ministry of Education China, China & $6(0.8)$ \\
\hline 16 th & Yale University, USA & $6(0.8)$ \\
\hline 16 th & The University of Hong Kong, Hong Kong & $6(0.8)$ \\
\hline 16 th & Fudan University, China & $6(0.8)$ \\
\hline 16 th & Hokkaido University, Japan & $6(0.8)$ \\
\hline 16 th & Sichuan University, China & $6(0.8)$ \\
\hline 16 th & National University of Singapore, Singapore & $6(0.8)$ \\
\hline 16 th & Western Sydney University, Australia & $6(0.8)$ \\
\hline 16 th & Université de Brest UBO, France & $6(0.8)$ \\
\hline 16 th & University of Oxford, UK & $6(0.8)$ \\
\hline 16 th & Lanzhou University, China & $6(0.8)$ \\
\hline 16 th & University of Alberta, Canada & $6(0.8)$ \\
\hline 16 th & The University of Queensland, Australia & $6(0.8)$ \\
\hline 16th & Michigan State University, USA & $6(0.8)$ \\
\hline
\end{tabular}

SCR standard competition ranking

${ }^{\text {a}}$ Equal institutions have the same number of ranking and then a gap is left in the number of rankings

${ }^{b}$ Percentage of documents/institution out of the total published research

were published in Science of the Total Environment journal. Most cited articles are discussing issues in relation to the association between environmental pollution and the diffusion of COVID-19. Other studies published in sources that link the environment with public health studied the effects of pandemic on the psychological aspects. In the list of most productive institutions, as shown in Table 4, institutions from China, where the outbreak of the pandemic was first detected, showed distinctive performance results at global level. The most productive institution was Chinese Academy of Sciences, China (24 documents; 
$3.3 \%$ ), followed by University of Chinese Academy of Sciences, China (15 documents; $2.1 \%$ ), and Università degli Studi di Napoli Federico II, Italy (14 documents; 1.9\%). Institutions from Italy, where the impacts of COVID-19 were at high levels across the globe at the early stages of the pandemic's outbreak, showed also remarkable performance with regard to research on COVID-19 in environmental sources. In case of China, there was 10 institutions in the list of top 20 most productive institutions, while, in case of Italy there was 5 institutions. One hundred fifty-nine authors had contributions on COVID-19 in environmental sources. Four researchers out of 10 prolific authors in the list of most productive authors on COVID-19 in environmental sources, as shown in Table 5, were from Italy, while the most prolific authors were Dewitte, J.D. from Université de Brest (UBO), Brest, France, Kitajima, M. from Hokkaido University, Sapporo, Japan, and Piscitelli, P. from Italian Society of Environmental Medicine (SIMA), Milan, Italy. Each author has 6 documents $(0.8 \%)$.

Network visualization map of co-occurrence of terms in the abstracts is displayed in Fig. 4. The least number of occurrences of a term was set as 10. Of the 13,060 terms, 456 terms met the proposed threshold. A relevance score, $60 \%$, is adopted. The most relevant terms were selected; 274 terms. The most occurrence term, after excluding COVID-19 and its related terms, was lockdown; 221 occurrences. It is followed by the term city; 220 occurrences, patient; 183 occurrences, concentration; 166 occurrences, period; 152 occurrences, reduction; 144 occurrences, temperature; 142 occurrences and death; 142 occurrences. The map categorized terms into 4 major clusters. Generally, these clusters can be classified as follows: cluster 1, yellow color, is in relation with environmental impacts of COVID-19. It describes how the lockdown due to the pandemic affected the air quality. Most works in this regard concluded that city lockdowns led to a sizeable improvement in air quality. Different studies showed that the positive effects of city lockdown on air quality are greater in cities with larger economies, greater industrial activities, and traffic volumes (He et al. 2020). These improvements in air quality due to lockdown are short-term effects if not sustainable measures are considered to sustain the behaviors of people during the lockdown (He et al. 2020). Furthermore, it examines the effects of air pollution on aggravating the impacts of COVID-19 on specific groups of people with respiratory diseases. Findings in relation to this issue concluded that people living in regions with high levels of pollutants are more prone to developing chronic respiratory conditions and suitable to infective agents (Conticini et al. 2020). Cluster 2 studies the metrological factors (weather, wind, precipitation) and their impacts on the diffusion of the pandemic. It is found that low temperatures, mild diurnal temperature range, and low level of humidity likely favor the transmission of the virus (Liu et al. 2020). Cluster 3 describes evidence-based methodologies to detect the presence of COVID-19 in water, air, and wastewater samples. In relation to wastewater, for example, different evidences from controlled experiments, previous outbreaks, and the current pandemic indicate that SARS-CoVs are present in wastewater for several days (Ahmed et al. 2020; Bogler et al. 2020). This could lead to health risks via waterborne (Bogler et al. 2020). Accordingly, numerous research works proposed the use of wastewater analyses as effective monitoring tools for viral pandemics and suggested the upgrading of existing wastewater systems to prevent viral diseases (Venugopal et al. 2020). The last cluster, cluster 4, with red color is highly related to public health. It describes the psychological impacts of COVID-19.

The content analysis conducted over abstracts of 4 most productive environmental sources based on the grouping of most frequent terms with stemmed words considering the top 500 most frequent terms with a minimum length of 3 characters indicates the major topics addressed by these sources (Fig. 5). There are high levels of similarity with regard to 


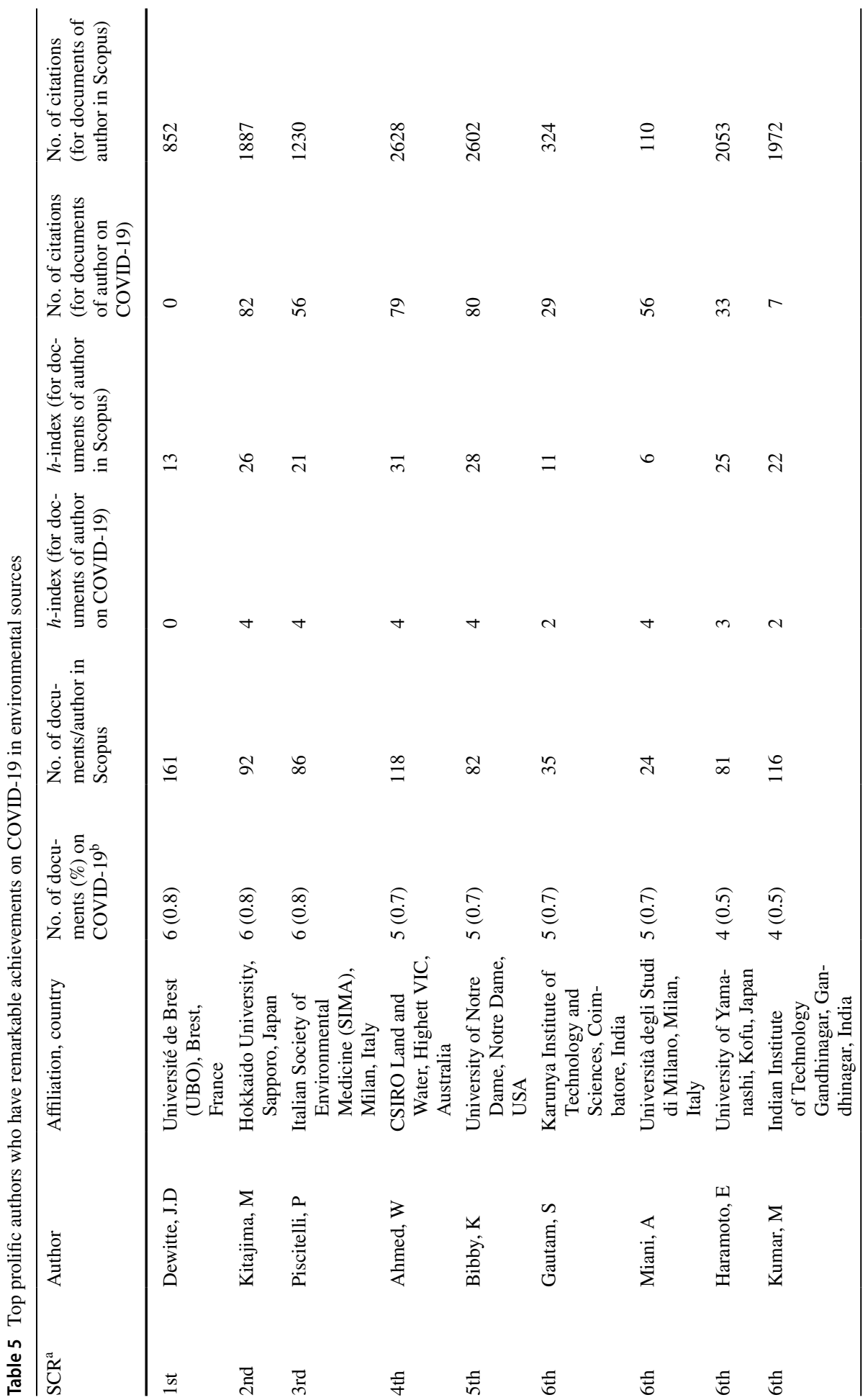




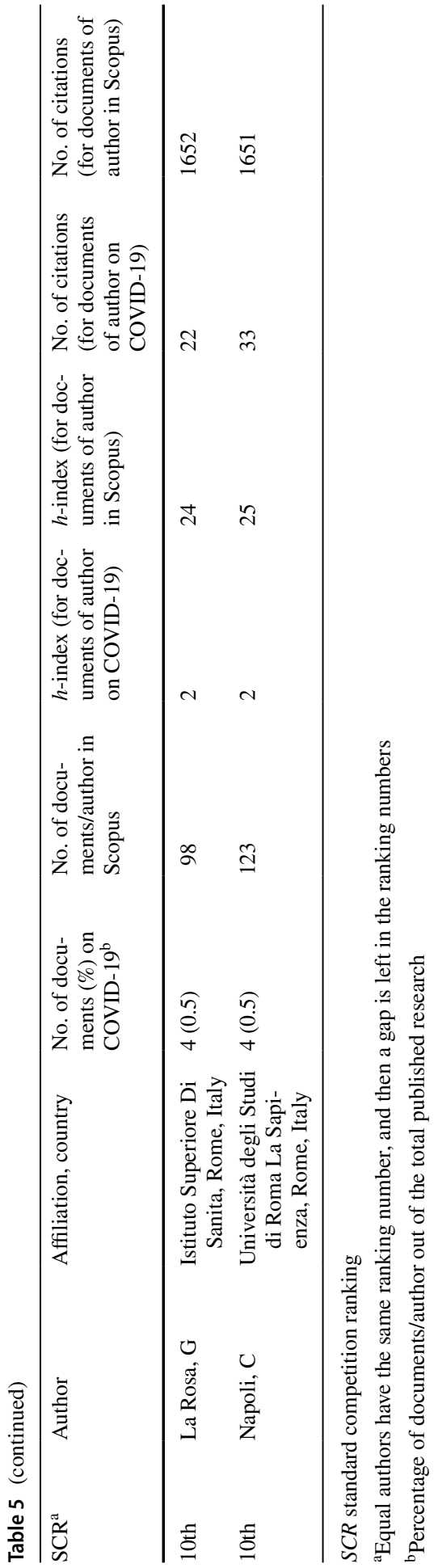

글 Springer 


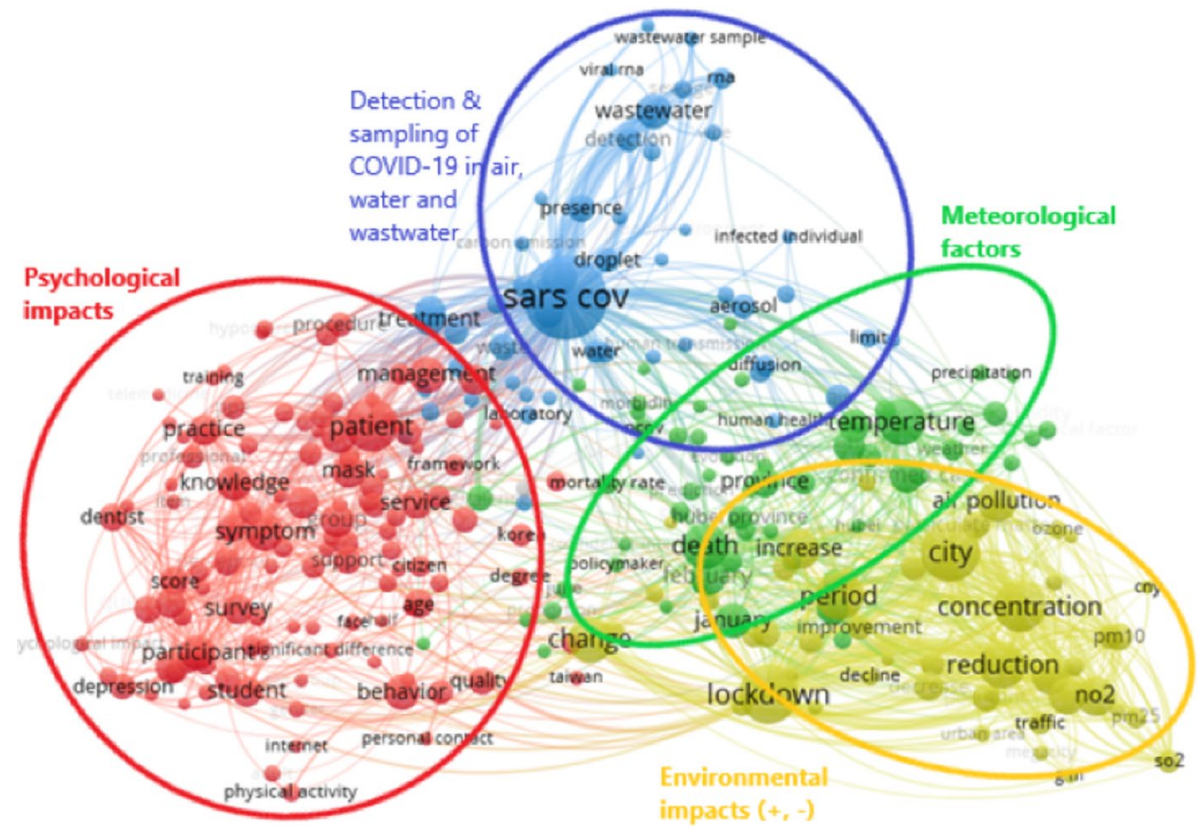

Fig. 4 Network visualization map, analysis of co-occurrence of terms in the abstracts, minimum number of occurrences of a term was set to 10, Of the 13,060 terms, 456 terms have met the specified threshold. For each of the 456 terms, a relevance score was proposed. Based on this score, the most relevant terms were selected. The default choice was $60 \%$ most relevant terms. The most relevant terms were selected; 274 terms classified in major 4 clusters

considered issues among the 4 sources: International Journal of Environmental Research and Public Health, Science of the Total Environment, Environmental Pollution, and Environmental and Resource Economics. The impacts of the pandemic on the public health, impacts of lockdown, factors of virus diffusion, and level of spread are among the major issues that have been discussed in these sources. International Journal of Environmental Research and Public Health focused on conducting studies in relation to assess the psychological impacts of the pandemic, impacts on mental health, risk perception, awareness among health workers, cross-sectional studies, and preventive measures. Science of the Total Environment addressed topics in relation to environmental impacts of the pandemic (i.e., improvements in air quality), the role of meteorological factors on the diffusion of the pandemic and detecting of COVID-19 in wastewater samples. Nearly the same topics have been discussed by Environmental Research journal with more focus on issues related to air pollution. Environmental and Resource Economics journal discussed topics in relation to behavioral patterns and economics during the pandemic, impacts of the pandemic on capital accumulation, macroeconomics, economic activities, power markets, and food supplies during the pandemic, and the recovery of commerce and economics.

A major negative environmental impact of COVID-19 is in relation to the medical wastes (Fig. 6). An explosion in the using of a specific type of medical supplies (i.e., disposal masks and gloves) has been witnessed. This has caused a fast increase in the quantities of medical wastes in healthcare facilities and further by people as measures to protect themselves. Other negative environmental impacts of COVID-19 include increasing 

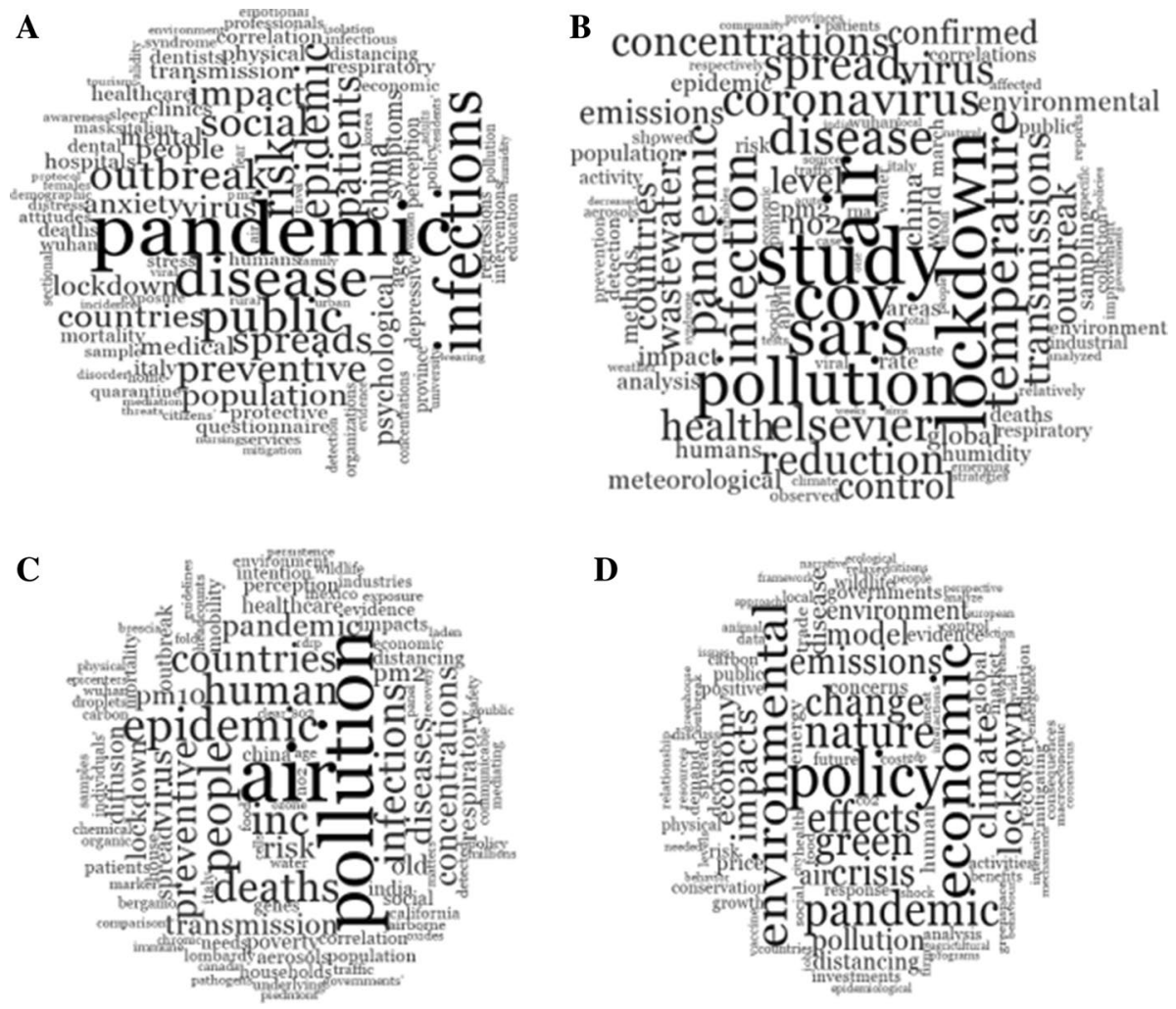

Fig. 5 Tag clouds of words appearing in the abstracts of 4 most productive environmental sources on COVID-19: a International Journal of Environmental Research and Public Health, b Science of the Total Environment, c Environmental Research, d Environmental and Resource Economics

of organic wastes by households due to quarantine policies, reduction in rates of wastes recycling; and increasing of disinfection rates of wastewaters as a measure to eliminate the diffusion of COVID-19 that could produce harmful impacts on the public health (Fig. 6) (Zambrano-Monserrate et al. 2020).

In terms of public health, people who are living in regions with high levels of air pollution and infected by COVID-19 are likely to be more susceptible to higher risks for significant illness and premature death. At the early phase of the pandemic outbreak, different studies reported great psychological impacts of COVID-19 and high levels of depression, stress, and anxiety among people (Wang et al. 2020). The updating in health information and different precautionary actions contribute to lower the psychological impacts of the outbreak (Wang et al. 2020).

With regard to the positive environmental impacts of COVID-19, improvements in air quality due to restrictions on mobility and reducing the industrial activities were well confirmed (Fig. 6). In China, for example, restrictions on traffic and quarantine measures caused $\mathrm{NO}_{2}$ to reduce by $22.8 \mu \mathrm{g} / \mathrm{m}^{3}$ and $12.9 \mu \mathrm{g} / \mathrm{m}^{3}$ in Wuhan and China, respectively. Concentrations of PM 2.5 are also dropped down (Zambrano-Monserrate et al. 2020). Reduction of noise levels and cleaning of beaches are further positive impacts of COVID-19 on the environment (Zambrano-Monserrate et al. 2020). Over the long term, 


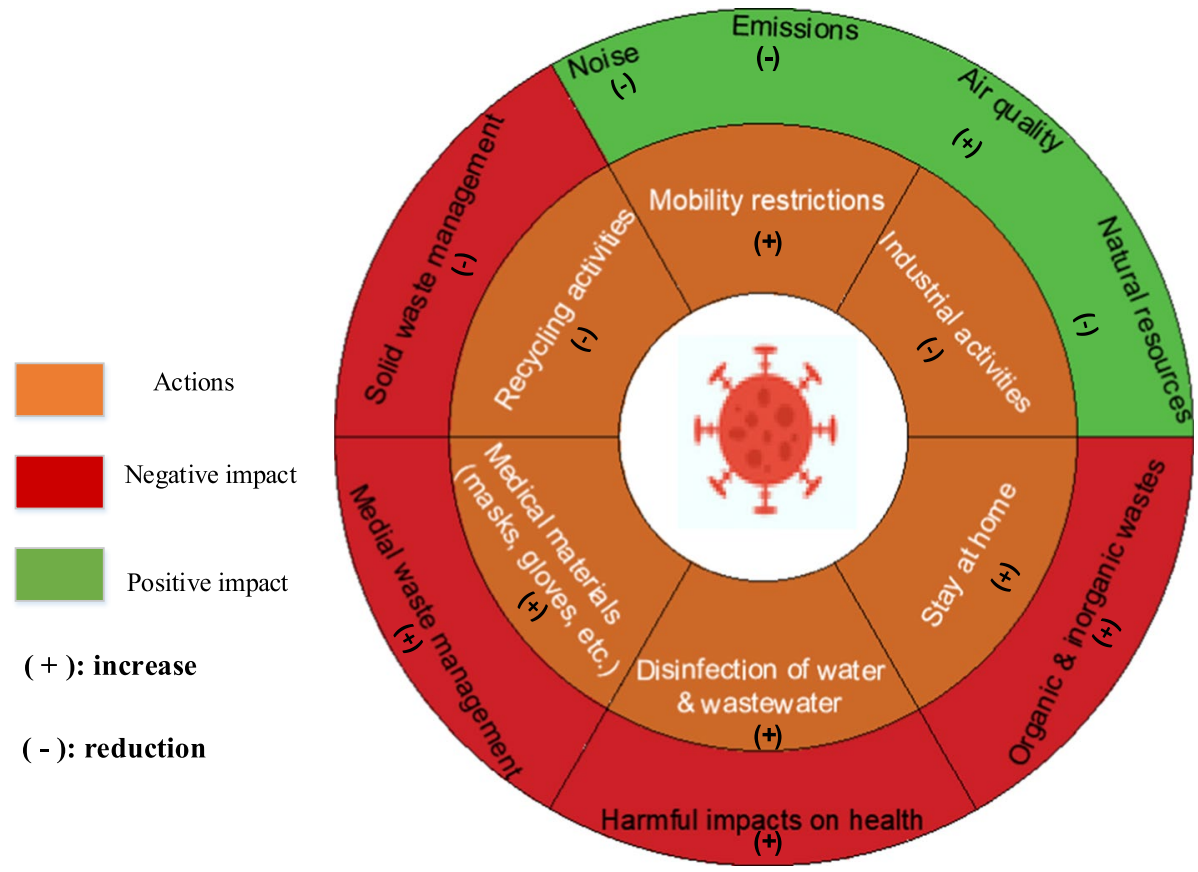

Fig. 6 Illustration of actions imposed to combat COVID-19 and their negative or positive impacts on the environment

identifying sustainable options to restrain pollution levels from rebounding or outreaching high levels after the dwindling of the pandemic is essential. Because it is expected that the economic activities at global level will return, the reduction in emissions during a short period is not a sustainable solution to clean up the environment (ZambranoMonserrate et al. 2020). The transportation sector and green recovery approaches, for example, are areas of intervention in this regard. This includes smart mobility based on adopting and maintaining flexible working schemes with less commuting, cars and bikes sharing, and well-developed public transportation systems.

Active themes of environmental research that can help in eliminate and mitigate the impacts of COVID-19 include: development of fast detection techniques of COVID-19 virus in wastewater systems, where the survival of the virus is well confirmed (Venugopal et al. 2020), as an early warning system to alert officials of public health about the diffusion of the virus in a specific community, and development of innovative techniques to disinfect large spaces (i.e., using ultraviolet light, electrostatic sprays, etc.) (Environemntal Protection Ageny (EPA) 2020). Other studies proposed additional water treatment steps as the current practices are not able to remove the SARS-CoV-2 completely (Venugopal et al. 2020). Venugopal et al. (2020) suggested the using of nanofiber filters as a pretreatment practice. This can be used as an effective monitoring tool and has a great potential in isolating viruses like SARS-CoV-2 (Venugopal et al. 2020). In pandemic hotspots, boiling of water as a home-made treatment, inactivation using ultraviolet irradiation, chlorination, and ultrafiltration are promising techniques to combat the pandemic (Venugopal et al. 2020). 


\section{Implications}

The outcomes of this bibliometric analysis have different major implications for assessment of the scientific output on COVID-19 in a collection of environmental sources. This analysis revealed a collection of key data and information where scientists, researchers, and decision makers can acquire insights into the contributions of countries, institutions, environmental sources, and authors in fields of research in relation to environment and COVID-19. The critical sources, renowned scholars, well-known institutions, and dominated countries in the field have been clearly revealed. The collaboration trends and efforts between countries, authors, and institutions at global scales have also clearly revealed and presented. The frontiers and hotspots of research traced and derived from related literature would provide sufficient details and even the prospective research and investment trends for researchers and decision makers. The resulted qualitative and quantitative indicators represent a base for future evaluation in relation to the scrutinized field. At the country level, for example, the productivity of countries can be used to identify the progress in the research productivity of these countries in the future. If a future assessment indicates that the productivity of a specific country is rising compared to the produced one in the present assessment, this would indicate the progress that a country is making toward advancing research in the field. This is applicable with respect to other bibliometric indicators (i.e., collaboration and citation rates). The identification of possible changes in research interests and trends compared to the existing ones is a further key implication of this analysis.

\section{Strengths and limitations}

Bibliometric and visualization analysis has been conducted to demonstrate the current status of COVID-19 research in environmental sources. This analysis, to the best of our knowledge, is the first of its type in the field. Research activities were evaluated from an overall point of view which could reveal the primary messages and core progress in this regard. As in most bibliometric analyses, some limitations are unavoidable. First, only the Scopus database was considered as a source of retrieving related works. For most indexed journals, Scopus database does not include the online versions of published works before inclusion in an issue (Falagas et al. 2008). Other databases, as the case of PubMed, are including online versions (Falagas et al. 2008). This may have excluded some relevant works published in other databases. Second, this analysis considered articles and review documents. The exclusion of other types of documents (i.e., letters, commentary, editorial, etc.) could omit some valuable information and contributions in the field. Third, citation rates which were elicited from Scopus database could be different compared to other databases. Despite that, Scopus database is commonly accepted by researchers for high-quality bibliometric analyses as it contains many features and having higher flexibility more than other databases. 


\section{Conclusions}

The conducting of global bibliometric analysis on COVID-19-related research activities in environmental sources was the primary issue of the present work. Various bibliometric indices (i.e., quantitative and qualitative ones) that are in relation to the performance of countries, sources, authors, institutions, etc., have been revealed, analyzed, and evaluated. Research collaboration analysis among countries, authors, institutions, and cocitation analysis of sources has been further conducted and discussed. An investigation of hot topics in the field and the future trends of research on COVID-19 in environmental sources was performed based on content analysis and clustering of terms frequency. Substantial research activities on COVID-19, mainly in relation to developing vaccines and curative medicines, have already begun extensively. Such activities on COVID-19 in environmental sources were modest as most efforts are devoted to saving the human existence. A promising environmental interest on COVID-19 will be witnessed in the near future. The identification of sustainable alternatives to restraint air pollution levels that have reduced during the pandemic will be a top priority. The developments in environmental research on COVID-19 will guide efforts of promoting global environmental strategies to control the different global environmental risks (i.e., air pollution, climate change, and environmental degradation) in the future.

Acknowledgements The authors would like to express their sincere gratitude to the reviewers for their suggestions and constructive comments to improve the quality of this article.

Author contributions Both authors ( $\mathrm{SHZ}$ and AHZ) contributed equally to this manuscript, initiated the study, designed and performed the analysis, interpreted the data, and wrote the main paper. All authors read and approved the final manuscript.

Funding No funding was received for writing this study.

Availability of data and materials The datasets used and/or analyzed during the current study are available from the corresponding author on reasonable request (shaher.zyoud@ptuk.edu.ps).

\section{Compliance with ethical standards}

Conflict of interest The authors declare that they have no conflict of interest.

Ethical approval No ethical approval was required, as this study is a bibliometric analysis of the existing literature.

Consent for publication Not applicable.

\section{References}

Ahmed, W., et al. (2020). First confirmed detection of SARS-CoV-2 in untreated wastewater in Australia: A proof of concept for the wastewater surveillance of COVID-19 in the community. Science of the Total Environment. https://doi.org/10.1016/j.scitotenv.2020.138764.

Aleixandre-Benavent, R., Aleixandre-Tudó, J. L., Castelló-Cogollos, L., \& Aleixandre, J. L. (2017). Trends in scientific research on climate change in agriculture and forestry subject areas (20052014. Journal of Cleaner Production, 147, 406-418. https://doi.org/10.1016/j.jclepro.2017.01.112. 
Arora, A. S., Rajput, H., \& Changotra, R. (2020). Current perspective of COVID-19 spread across South Korea: Exploratory data analysis and containment of the pandemic Environment. Development and Sustainability. https://doi.org/10.1007/s10668-020-00883-y.

Bogler, A., et al. (2020). Rethinking wastewater risks and monitoring in light of the COVID-19 pandemic. Nature Sustainability. https://doi.org/10.1038/s41893-020-00605-2.

Bornmann, L. (2016). Is the promotion of research reflected in bibliometric data? A network analysis of highly cited papers on the Clusters of Excellence supported under the Excellence Initiative in Germany. Scientometrics, 107, 1041-1061. https://doi.org/10.1007/s11192-016-1925-2.

Chan, J. F. W., et al. (2020). Improved molecular diagnosis of COVID-19 by the novel, highly sensitive and specific COVID-19-RdRp/Hel real-time reverse transcription-PCR assay validated in vitro and with clinical specimens. Journal of Clinical Microbiology, 58, e00310-20.

Changotra, R., Rajput, H., Rajput, P., Gautam, S., \& Arora, A. S. (2020). Largest democracy in the world crippled by COVID-19: Current perspective and experience from India Environment. Development and Sustainability. https://doi.org/10.1007/s10668-020-00963-z.

Chen, C. (2004). Searching for intellectual turning points: Progressive knowledge domain visualization. Proceedings of the National Academy of Sciences, 101, 5303-5310. https://doi.org/10.1073/ pnas.0307513100.

Chen, J. (2020). Pathogenicity and transmissibility of 2019-nCoV-A quick overview and comparison with other emerging viruses. Microbes and Infection, 22, 69-71. https://doi.org/10.1016/j.micin f.2020.01.004.

Conticini, E., Frediani, B., \& Caro, D. (2020). Can atmospheric pollution be considered a co-factor in extremely high level of SARS-CoV-2 lethality in Northern Italy? Environmental Pollution. https://doi. org/10.1016/j.envpol.2020.114465.

Du, H., Li, N., Brown, M. A., Peng, Y., \& Shuai, Y. (2014). A bibliographic analysis of recent solar energy literatures: The expansion and evolution of a research field. Renewable Energy, 66, 696-706. https:// doi.org/10.1016/j.renene.2014.01.018.

Dutheil, F., Baker, J. S., \& Navel, V. (2020). COVID-19 as a factor influencing air pollution? Environmental Pollution, 263, 114466. https://doi.org/10.1016/j.envpol.2020.114466.

Environemntal Protection Ageny (EPA) (2020) Research on COVID-19 in the Environment. Retrieved August 17, 2020, from https://www.epa.gov/healthresearch/research-covid-19-environment.

Falagas, M. E., Pitsouni, E. I., Malietzis, G. A., \& Pappas, G. (2008). Comparison of PubMed, Scopus, Web of Science, and Google Scholar: strengths and weaknesses. FASEB Journal: Official Publication of the Federation of American Societies for Experimental Biology, 22, 338-342. https://doi.org/10.1096/ fj.07-9492LSF.

Fan, J., et al. (2020). Bibliometric analysis on COVID-19: A comparison of research between English and Chinese studies. Frontiers in Public Health. https://doi.org/10.3389/fpubh.2020.00477.

Gallegos, M., et al. (2020). COVID-19 in Latin America: A bibliometric analysis of scientific publications in health. Electronic Journal of General Medicine, 17, 1-7. https://doi.org/10.29333/ejgm/8460.

Habibzadeh, P., \& Stoneman, E. K. (2020). The novel coronavirus: A bird's eye view International. Journal of Occupational and Environmental Medicine, 11, 65-71. https://doi.org/10.15171/ijoem.2020.1921.

Harapan, H., et al. (2020). Coronavirus disease 2019 (COVID-19): A literature review. Journal of Infection and Public Health, 13, 667-673. https://doi.org/10.1016/j.jiph.2020.03.019.

Havemann, F., Heinz, M., \& Kretschmer, H. (2006). Collaboration and distances between German immunological institutes-A trend analysis. Journal of Biomedical Discovery and Collaboration, 1, 6.

He, G., Pan, Y., \& Tanaka, T. (2020). The short-term impacts of COVID-19 lockdown on urban air pollution in China. Nature Sustainability. https://doi.org/10.1038/s41893-020-0581-y.

Heymann, D. L., \& Shindo, N. (2020). COVID-19: What is next for public health? The Lancet, 395, 542545. https://doi.org/10.1016/S0140-6736(20)30374-3.

Hirsch, J. E. (2005). An index to quantify an individual's scientific research output. Proceedings of the National Academy of Sciences of the United States of America, 102, 16569-16572. https://doi. org/10.1073/pnas.0507655102.

Iyer, M., Jayaramayya, K., Subramaniam, M. D., Lee, S. B., Dayem, A. A., Cho, S.-G., et al. (2020). COVID-19: An update on diagnostic and therapeutic approaches. BMB Reports, 53, 191-205. https:// doi.org/10.5483/BMBRep.2020.53.4.080.

Kambhampati, S. B., Vaishya, R., \& Vaish, A. (2020). Unprecedented surge in publications related to COVID-19 in the first three months of pandemic: A bibliometric analytic report. Journal of Clinical Orthopaedics and Trauma, 11, S304.

Kampf, G., Todt, D., Pfaender, S., \& Steinmann, E. (2020). Persistence of coronaviruses on inanimate surfaces and their inactivation with biocidal agents. Journal of Hospital Infection, 104, 246-251. https:// doi.org/10.1016/j.jhin.2020.01.022. 
Li, S., Wang, Y., Xue, J., Zhao, N., \& Zhu, T. (2020). The impact of covid-19 epidemic declaration on psychological consequences: A study on active weibo users. International Journal of Environmental Research and Public Health. https://doi.org/10.3390/ijerph17062032.

Liu, J., et al. (2020). Impact of meteorological factors on the COVID-19 transmission: A multi-city study in China. Science of the Total Environment. https://doi.org/10.1016/j.scitotenv.2020.138513.

Lou, J., Tian, S. J., Niu, S. M., Kang, X. Q., Lian, H. X., Zhang, L. X., et al. (2020). Coronavirus disease 2019: A bibliometric analysis and review. European Review for Medical and Pharmacological Sciences, 24, 3411-3421. https://doi.org/10.26355/eurrev_202003_20712.

Lu, R., et al. (2020). Genomic characterisation and epidemiology of 2019 novel coronavirus: Implications for virus origins and receptor binding. The Lancet, 395, 565-574. https://doi.org/10.1016/ S0140-6736(20)30251-8.

Ma, Y., et al. (2020). Effects of temperature variation and humidity on the death of COVID-19 in Wuhan. China Science of the Total Environment. https://doi.org/10.1016/j.scitotenv.2020.138226.

Mao, X., Guo, L., Fu, P., \& Xiang, C. (2020). The status and trends of coronavirus research: A global bibliometric and visualized analysis. Medicine, 99, e20137. https://doi.org/10.1097/md.00000 00000020137

Martín-Martín, A., Orduna-Malea, E., Thelwall, M., \& Delgado López-Cózar, E. (2018). Google Scholar, Web of Science, and Scopus: A systematic comparison of citations in 252 subject categories. Journal of Informetrics, 12, 1160-1177. https://doi.org/10.1016/j.joi.2018.09.002.

Meho, L. I., \& Rogers, Y. (2008). Citation counting, citation ranking, and h-index of human-computer interaction researchers: A comparison of Scopus and Web of Science. Journal of the American Society for Information Science and Technology, 59, 1711-1726. https://doi.org/10.1002/asi.20874.

Merigó, J. M., Blanco-Mesa, F., Gil-Lafuente, A. M., \& Yager, R. R. (2017). Thirty years of the international journal of intelligent systems: A bibliometric review. International Journal of Intelligent Systems, 32, 526-554. https://doi.org/10.1002/int.21859.

Mohadab, M. E., Bouikhalene, B., \& Safi, S. (2020). Bibliometric method for mapping the state of the art of scientific production in Covid-19 Chaos. Solitons \& Fractals, 139, 110052. https://doi. org/10.1016/j.chaos.2020.110052.

Morawska, L., \& Cao, J. (2020). Airborne transmission of SARS-CoV-2: The world should face the reality. Environment International. https://doi.org/10.1016/j.envint.2020.105730.

Muhammad, S., Long, X., \& Salman, M. (2020). COVID-19 pandemic and environmental pollution: A blessing in disguise? Science of the Total Environment, 728, 138820. https://doi.org/10.1016/j.scito tenv.2020.138820.

NVIVO. (2020). Unlock insights in your data with powerful analysis. Retrieved May, 2020, from https:// www.qsrinternational.com/nvivo-qualitative-data-analysis-software/home.

Ogen, Y. (2020). Assessing nitrogen dioxide $\left(\mathrm{NO}_{2}\right)$ levels as a contributing factor to coronavirus (COVID-19) fatality. Science of the Total Environment. https://doi.org/10.1016/j.scito tenv.2020.138605.

Oh, J., \& Kim, A. (2020). A bibliometric analysis of COVID-19 research published in nursing journals. Science Editing, 7, 118-124. https://doi.org/10.6087/KCSE.205.

Rajput, H., Changotra, R., Rajput, P., Gautam, S., Gollakota, A. R. K., \& Arora, A. S. (2020). A shock like no other: Coronavirus rattles commodity markets. Environment, Development and Sustainability. https://doi.org/10.1007/s10668-020-00934-4.

Raju, N. V., \& Patil, S. B. (2020). Indian publications on SARS-CoV-2: A bibliometric study of WHO COVID-19 database. Diabetes and Metabolic Syndrome: Clinical Research and Reviews, 14, 11711178. https://doi.org/10.1016/j.dsx.2020.07.007.

Romero, L., \& Portillo-Salido, E. (2019). Trends in sigma-1 receptor research: a 25-year bibliometric analysis. Frontiers in Pharmacology. https://doi.org/10.3389/fphar.2019.00564.

Setti, L., et al. (2020). Airborne transmission route of covid-19: Why 2 meters/6 feet of inter-personal distance could not be enough. International Journal of Environmental Research and Public Health. https://doi.org/10.3390/ijerph17082932.

Sharma, S., Zhang, M., Gao, J., Zhang, H., \& Kota, S. H. (2020). Effect of restricted emissions during COVID-19 on air quality in India. Science of the Total Environment. https://doi.org/10.1016/j.scito tenv.2020.138878.

Song, P., \& Karako, T. (2020). COVID-19: Real-time dissemination of scientific information to fight a public health emergency of international concern. Bioscience Trends, 14, 1-2. https://doi. org/10.5582/bst.2020.01056.

Tobías, A., et al. (2020). Changes in air quality during the lockdown in Barcelona (Spain) one month into the SARS-CoV-2 epidemic. Science of the Total Environment. https://doi.org/10.1016/j.scito tenv.2020.138540. 
Tosepu, R., Gunawan, J., Effendy, D. S., Ahmad, L. O. A. I., Lestari, H., Bahar, H., et al. (2020). Correlation between weather and Covid-19 pandemic in Jakarta. Indonesia Science of the Total Environment. https://doi.org/10.1016/j.scitotenv.2020.138436.

van Eck, N. J., \& Waltman, L. (2010). Software survey: VOSviewer, a computer program for bibliometric mapping. Scientometrics, 84, 523-538. https://doi.org/10.1007/s11192-009-0146-3.

Vellingiri, B., et al. (2020). COVID-19: A promising cure for the global panic. Science of the Total Environment. https://doi.org/10.1016/j.scitotenv.2020.138277.

Venugopal, A., et al. (2020). Novel wastewater surveillance strategy for early detection of coronavirus disease 2019 hotspots. Current Opinion in Environmental Science \& Health, 17, 8-13. https://doi. org/10.1016/j.coesh.2020.05.003.

Verma, S., \& Gustafsson, A. (2020). Investigating the emerging COVID-19 research trends in the field of business and management: A bibliometric analysis approach. Journal of Business Research, 118, 253-261. https://doi.org/10.1016/j.jbusres.2020.06.057.

Wallin, J. A. (2005). Bibliometric methods: Pitfalls and possibilities. Basic \& Clinical Pharmacology \& Toxicology, 97, 261-275. https://doi.org/10.1111/j.1742-7843.2005.pto_139.x.

Wang, C., Pan, R., Wan, X., Tan, Y., Xu, L., Ho, C. S., et al. (2020). Immediate psychological responses and associated factors during the initial stage of the 2019 coronavirus disease (COVID-19) epidemic among the general population in China. International Journal of Environmental Research and Public Health, 17, 1729. https://doi.org/10.3390/ijerph17051729.

Wang, L., Zhao, L., Mao, G., Zuo, J., \& Du, H. (2017). Way to accomplish low carbon development transformation: A bibliometric analysis during 1995-2014. Renewable and Sustainable Energy Reviews, 68, 57-69. https://doi.org/10.1016/j.rser.2016.08.021.

World Health Organization W. (2020). Coronavirus disease (COVID-19) pandemic. Retrieved August 12, 2020, from https://www.who.int/emergencies/diseases/novel-coronavirus-2019.

$\mathrm{Wu}, \mathrm{Y}$., et al. (2020). SARS-CoV-2 is an appropriate name for the new coronavirus. The Lancet, 395 , 949-950. https://doi.org/10.1016/S0140-6736(20)30557-2.

Xie, J., \& Zhu, Y. (2020). Association between ambient temperature and COVID-19 infection in 122 cities from China. Science of the Total Environment. https://doi.org/10.1016/j.scitotenv.2020.138201.

Yataganbaba, A., \& Kurtbaş, I. (2016). A scientific approach with bibliometric analysis related to brick and tile drying: A review. Renewable and Sustainable Energy Reviews, 59, 206-224. https://doi. org/10.1016/j.rser.2015.12.357.

Zambrano-Monserrate, M. A., Ruano, M. A., \& Sanchez-Alcalde, L. (2020). Indirect effects of COVID19 on the environment. Science of the Total Environment, 728, 138813. https://doi.org/10.1016/j. scitotenv.2020.138813.

Zhai, F., et al. (2020). Research progress of coronavirus based on bibliometric analysis. International Journal of Environmental Research and Public Health, 17, 3766.

Zhang, H., \& Shaw, R. (2020). Identifying research trends and gaps in the context of COVID-19. International Journal of Environmental Research and Public Health, 17, 3370.

Zhang, Y., \& Ma, Z. F. (2020). Impact of the COVID-19 pandemic on mental health and quality of life among local residents in Liaoning Province, China: A cross-sectional study. International Journal of Environmental Research and Public Health. https://doi.org/10.3390/ijerph17072381.

Zhang, Y., Pu, S., Lv, X., Gao, Y., \& Ge, L. (2020). Global trends and prospects in microplastics research: A bibliometric analysis. Journal of Hazardous Materials, 400, 123110. https://doi. org/10.1016/j.jhazmat.2020.123110.

Zheng, T., Li, P., Shi, Z., \& Liu, J. (2017). Benchmarking the scientific research on wastewater-energy nexus by using bibliometric analysis. Environmental Science and Pollution Research, 24, 2761327630. https://doi.org/10.1007/s11356-017-0696-5.

Zheng, T., Li, P., Wu, W., Liu, J., Shi, Z., Guo, X., et al. (2018). State of the art on granular sludge by using bibliometric analysis. Applied Microbiology and Biotechnology, 102, 3453-3473. https://doi. org/10.1007/s00253-018-8844-5.

Zhu, Y., Xie, J., Huang, F., \& Cao, L. (2020). Association between short-term exposure to air pollution and COVID-19 infection: Evidence from China. Science of the Total Environment. https://doi. org/10.1016/j.scitotenv.2020.138704.

Zyoud, S. H., \& Al-Jabi, S. W. (2020). Mapping the situation of research on coronavirus disease-19 (COVID-19): A preliminary bibliometric analysis during the early stage of the outbreak. $B M C$ Infectious Diseases, 20, 561. https://doi.org/10.1186/s12879-020-05293-z.

Zyoud, S. H., \& Fuchs-Hanusch, D. (2015). Estimates of Arab world research productivity associated with desalination: A bibliometric analysis IDA. Journal of Desalination and Water Reuse, 7, 3-16. https://doi.org/10.1179/2051645215Y.0000000001. 
Zyoud, S. H., \& Fuchs-Hanusch, D. (2017). Estimates of Arab world research productivity associated with groundwater: A bibliometric analysis. Applied Water Science, 7, 1255-1272. https://doi.org/10.1007/ s13201-016-0520-2.

Zyoud, S. H., \& Fuchs-Hanusch, D. (2020). Mapping of climate change research in the Arab world: A bibliometric analysis. Environmental Science and Pollution Research, 27, 3523-3540. https://doi. org/10.1007/s11356-019-07100-y.

Publisher's Note Springer Nature remains neutral with regard to jurisdictional claims in published maps and institutional affiliations. 